

\section{LEGAL NOTICE}

This report was prepared as an account of Government sponsored work. Neither the United States, nor the Commission, nor any person acting on behalf of the Commission:

A. Makes any warranty or representation, expressed or implled, with respect to the accuracy, completeness, or usefulness of the information contained in this report, or that the use of any information, apparatus, method, or process disclosed in this report may not infringe privately owned rights; or

B. Assumes any liabilities with respect to the use of, or for damages resulting from the use of any information, apparatus, method, or process disclosed in this report.

As used In the above, "person acting on behalf of the Commission" includes any employee or contractor of the Commission, or employee of such contractor, to the extent that such employee or contractor of the Commission, or employee of such contractor prepares, disseminates, or provides access to, any information pursuant to his employment or contract with the Commission, or his employment with such contractor.

Printed in USA. Price $\$ 1.00$

Avallable from the Clearinghouse for Federal Sclentific and Technical Information, National Bureau of Standards,

U. S. Department of Commerce, Springfleld, Virginia 


\title{
A PORTABLE MULTIPURPOSE RADIATION MONITOR
}

\author{
by \\ William F. Splichal, Jr. \\ Approved by \\ C. M. Patterson, Research Manager \\ Radiological and Environmental Sciences Division
}

May 1966

E. I. DU PONT DE NEMOURS \& COMPANY

SAVANNAH RIVER LABORATORY

AIKEN, SOUTH CAROLINA 29801

CONTRACT AT(07.2).1 WITH THE

UNITED STATES ATOMIC ENERGY COMMISSION 


\section{ABSTRACT}

A basic electronic package for a portable multipurpose radiation monitor was designed, fabricated, and fleld tested. Transistorized plug-in clrcults powered by rechargeable nickel-cadmlum batterles, a readout meter, and an electromechanlcal register are contalned in a 4" $x 5^{\prime \prime} \times$ 6" case. Three rate meter ranges, a battery check position, and a register integrator for low rates are provided. The circultry contains seven silicon transistors on four plug-in cards. Neutron, alpha, beta-gamma, or alpha-beta-gamma detectors can be ind1vidualiy coupled to the electronic package. Calibration for each detector is simple and stable because the package is unaffected by temperature changes between 20 and $100^{\circ} \mathrm{F}$. The monitor welghs about seven pounds, can be carried in one hand, requires no warmup period, and is easy to operate and service. 


\section{CONTENTS}

Page

Introduction

1

Summary

Discussion

Electronic Circuit Operation

Neutron Detector

Alpha Detector

Beta-Gamma Detector

Alpha-Beta-Gamma Detector

Reference

LIST OF FIGURES

F1gure

1 Bas1c Electronic Package Circuitry

2 Neutron Detector

2

5

3 "Luc1te" Cone-Shaped Light P1pe and Polyethylene Cylinder

1

1

1

4

6

8

9

10

4 Alpha Detector

5

5 Beta-Gamma Detector

7

6 Alpha-Beta-Gamma Detector

* Du Pont's trade-mark for acrylic resins. 


\title{
A PORTABLE MULTIPURPOSE RADIATION MONITOR
}

\author{
INTRODUCTION
}

Portable radiation survey instruments have been developed that use a single basic electronic package and various types of radiation detectors. This basic package with a series of detectors can measure alpha, beta, gamma (semiquant1tatively), and neutrons. Plug-in electronic c1rcult cards and rechargeable batteries reduce and simplify maintenance and spare parts inventory. The instrument welghs about seven pounds, and the basic package 1s $4^{\prime \prime} \times 5^{\prime \prime} \times 6^{\prime \prime}$.

\section{SUMMARY}

Three electronic packages were designed and fleld tested with different types of detectors. All instruments performed satisfactorily. These prototypes demonstrated that a single electronic package can be used with four different types of radiation detectors. The life of the instruments in fleld use was greatly increased by using rechargeable batterles. During a 6-month field test, the three instruments required neither recalibration nor maintenance.

\section{DISCUSSION}

\section{ELECTRONIC CIRCUIT OPERATION}

The circuitry, Figure 1, uses a minimum of components and circuits. To further aid in quick and easy repair of the basic package, almost all components other than the meter, register, and selector switch are on plug-in cards that can be replaced as units. Silicon transistors minimize temperature-dependence effects.

The Dumont 6291 photomultiplier (PM) tube, which is used with three of the radiation detectors, and the high voltage divider network are in a detachable probe connected to the instrument case by a coaxial colled cord. Bypass capacitors in the last two dynode stages of the PM tube ensure peak currents from a detector scintillation that exceeds the average dynode string current.

The preamplifier plug-in card contains the signal developing resistor, emitter follower, and two stages of amplification. The negative scintillation pulses developed across the PM tube anode 


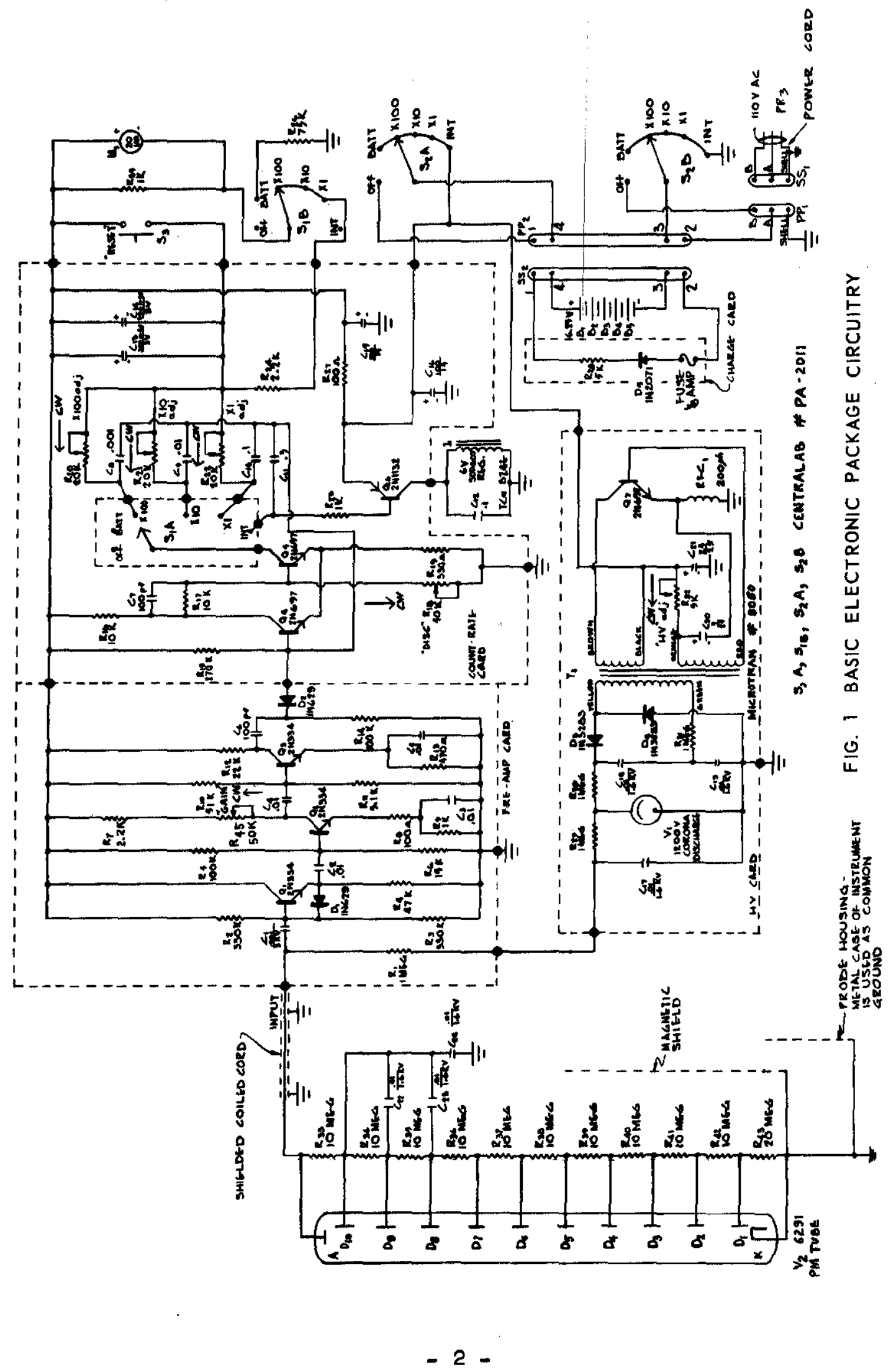


resistor $R_{1}$ are coupled to the base of $Q_{1}$, an emitter follower stage, via $C_{1} . D_{1}$ prevents burnout of the transistor by high voltage transients that are generated when the instrument is turned off. The negative pulses are coupled from the emitter follower to the first of two common-emitter amplifier stages, $Q_{2}$ and $Q_{3}$. The voltage gain in these two stages is approximately 60 and is controlled by potentiometer $R_{45}$; negative feedback in the emitters of both $Q_{2}$ and $Q_{3}$ ensures stability. The output of the preamplifier card through $D_{2}$ ensures that only negative pulses without any positive overshoot are coupled to the multivibrator stage.

The count-rate plug-in card contains a monostable multivibrator consisting of $Q_{4}$ and $Q_{5}$ and a register drive $Q_{8}$. In the monostable multivibrator, $Q_{4}$ is normally conducting and $Q_{5}$ is cut off by the voltage from the blasing network $R_{16}, R_{17}$, and $R_{18}$. Incoming negative pulses to the base of $Q_{4}$, a result of a scintillation, cut off $Q_{4}$, producing a positive pulse at the collector of $Q_{4}$ that is coupled to the base of $Q_{5}$ via $C_{7}$; Potentiometer $R_{18}$ as a pulse height discriminator control allows the bias of $Q_{5}$ to be adjusted to reject the smaller scintillation pulses from gamma radiation and noise. The perlod during which $Q_{5}$ conducts is determined by the time required for the capacitor in the collector circuit of $Q_{5}$ to discharge sufficiently to bring the base of $Q_{4}$ back to a voltage blas point, thereby re-establishing conduction within $Q_{4}$. The negative pulse produced at the collector of $Q_{4}$ is then coupled via $C_{7}$ to cut off conduction within $Q_{5}$ and return the clrcuit to its initial state.

As a result of $Q_{5}$ being turned on, a negative square wave voltage pulse drawn through the meter circuit causes an up-scale reading. The meter deflection per pulse is determined by the value of the $Q_{5}$ collector capacitor used to gate the multivibrator. For higher counting rates, the use of a smaller value capacitor reduces the conduction time of $Q_{5}$ which reduces scale deflection per scintillation pulse. The meter movement is: shunted by $\mathrm{C}_{13}$ and $\mathrm{C}_{14}$ to smooth out the $Q_{5}$ voltage pulses and to provide a uniform meter deflection. Potentlometers $R_{20}, R_{21}$, and $R_{22}$ are used to calibrate the rate meter scales. Reset switch $\mathrm{S}_{3}$ discharges $\mathrm{C}_{13}$ and $\mathrm{C}_{14}$ and allows the meter to be quickly returned to zero after a high meter reading.

In the register integrate position, PNP silicon transistor $Q_{8}$ replaces the meter circuit in the collector circuit of $Q_{5}$. Conduction of $Q_{5}$, as a result of a scintillation pulse, blases $Q_{B}$ into the conduction state. The collector circuit of $Q_{B}$ contains a Sodeco register that cycles for each gating of $Q_{B}$. Capacitor $\mathrm{C}_{11}$ determines the gating time of the multivibrator, which must be sufficient to allow the register to cycle mechanically. 
The high voltage plug-in card contains a DC to DC converter which develops 1200 volts for the PM tube dynode string. $Q_{7}$ is used in a blocking circuit that osclllates at approximately 800 cycles per second. Potentiometer $R_{32}$ is used to adjust the frequency of the oscillations to provide 1200 volts across the corona discharge tube $\mathrm{V}_{1}$. This oscillator draws approximately $16 \mathrm{ma}$. The voltage generated in the secondary of $T_{1}$ is connected to a voltage doubler that develops slightly more than 1200 volts. Corona discharge tube $v_{1}$ regulates this high voltage to 1200 volts.

The charge plug-in card contains a fuse, halfwave rectifier $D_{5}$, and voltage dropping resistor $R_{28}$. Under normal charging conditions, the current is approximately 10 to $15 \mathrm{ma}$, depending on the voltage of the nickel-cadmium battery at the time of recharging. These batteries are never to be recharged for periods longer than 72 hours. Four 1.5-volt D-size flashlight batteries with a shorting wire across one of the five battery positions may be used to replace the five 1.25-volt nickel-cadmium batteries. A battery check position on the selector switch indicates the condition of the rechargeable batteries; the battery voltages are checked while under the normal operating current load, and the meter is switched across the batteries as a voltmeter.

Calibration of the instrument for a particular detector is simple and stable over long perlods of time and remains unchanged between 20 and $100^{\circ} \mathrm{F}$. The instrument with any of the four different detectors can be carried in one hand, is easy to operate and read, and requires no warmup.

\section{NEUTRON DETECTOR}

The first prototype (see Figure 2) was a scintillation dosimeter for fast neutrons. Advantages over present instruments are:

- Low initial cost

- Effective discrimination against gamma radiation

- Convenient size and weight

- Nondirectional

- Sensitive to low neutron flux densities.

A unique feature of this instrument is the relatively simple fast detector which detects neutrons by the $(n, p)$ scattering process. Because the radiation dose received by tissue exposed to fast neutrons is energy dependent, the detector was designed to attain a response proportional to that of tissue. This is 
FIG. 2

NEUTRON DETECTOR

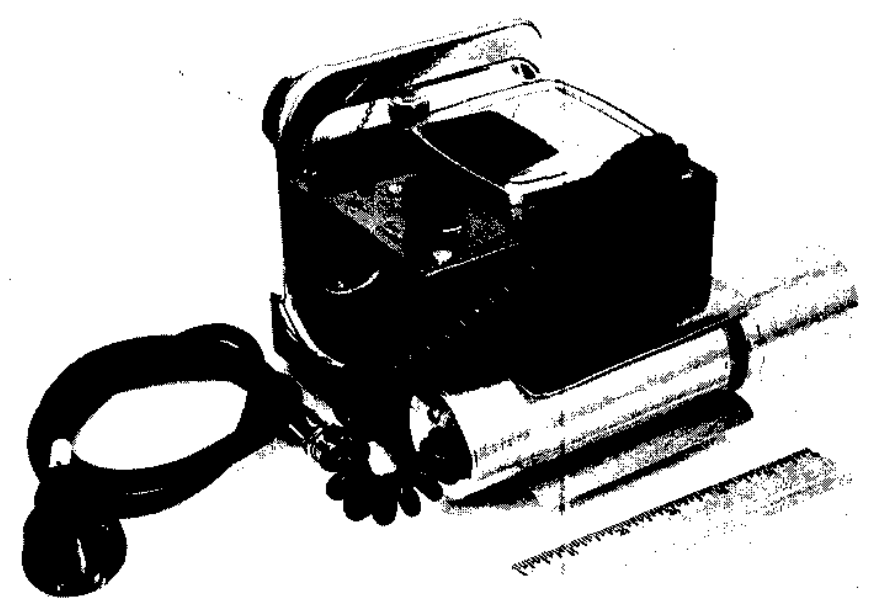

accomplished by a polyethylene moderating cylinder containing a "Lucite" cone-shaped light pipe in intimate contact with a Dumont 6291 PM tube (see Figure 3); the slanting surface of the cone is coated with silver-activated $\mathrm{ZnS}\left(9 \mathrm{mg} / \mathrm{m}^{2}\right)$. The high specific ionization of the recoil protons from the $(n, p)$ reaction with hydrogen in the polyethylene produces scintillations within a $\mathrm{ZnS}(\mathrm{Ag})$ phosphor. Polyethylene has a relatively large cross section for the $(n, p)$ reaction. The resultant recoli protons transfer their energy within a distance of less than 100 microns. (1) The conical scintillation surface compensates for faster neutrons by providing a greater scintillation area with increasing depth in the hydrogenous moderator. The shape and size of the detector were empirically determined to achieve an approximate tissue response for neutrons from 0.2 to $10 \mathrm{Mev}$. Larger light pulses from the proton interaction with $\mathrm{ZnS}(\mathrm{Ag})$ are counted, but the smaller pulses from the gamma radiation are electronicaliy refected. The symmetrical conical surface allows the detector to be relatively insensitive to directional effects.

FIG. 3

"LUCITE" CONE - SHAPED LIGHT PIPE AND POLYETHYLENE CYL.

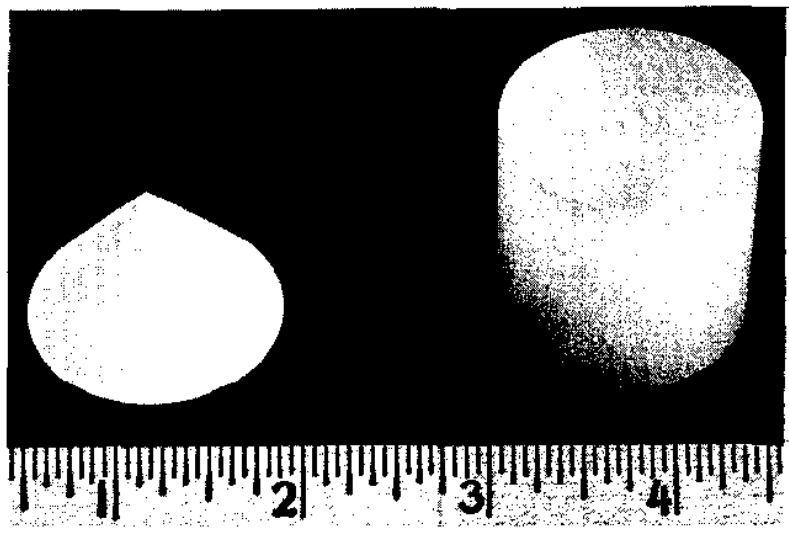


In comparison with three commerclally avallable neutron dose measuring instruments, the detector accurately measured neutron dose rates from a varlety of complex neutron energy spectra over an energy range from 0.2 to $10 \mathrm{Mev}$. Three neutron dose rate meter ranges of 0 to 50,500 , and $5000 \mathrm{mRem} / \mathrm{hr} *$, and a register integrator for low rates are provided. The detachable neutron detector probe (8" long x 1.75" dlameter) can be used for glove port monitoring or in other limited spaces. With an electronic discrimination setting to allow only $10-20 \mathrm{c} / \mathrm{m}$ in a $5 \mathrm{R} / \mathrm{hr}$ gamma fleld, the fast neutron response is approximately $4 \mathrm{c} / \mathrm{m} / \mathrm{mRem} / \mathrm{hr}$.

\section{ALPHA DETECTOR}

The second prototype was an alpha scintillation detector (see Figure 4) w1th a uniform response over the entire clrcular detection area of $100 \mathrm{~cm}^{2}$. The detector 1s $4-1 / 2$ "diameter $x$ $1 / 32$ "-thick "Luc1te" that is sprayed on one side with approximately $10 \mathrm{mg} / \mathrm{cm}$ of $\mathrm{ZnS}(\mathrm{Ag})$. The outward side of the scintillation area with the sprayed phosphor is covered with two layers of 0.00015-inch double aluminized "Mylar"**, which allows the detector to be used in direct sunlight. A 1-1/2" Dumont 6291 PM tube detects scintillations occurring on the fluorescent surface.

The high scintillation efflciency of $\mathrm{ZnS}(\mathrm{Ag})$ for alpha particles and its relative insentitivity to gamma rays allow electronic discrimination of the smaller gamma pulses. No light plpe is used in the two-inch distance between the scintillation surface and the PM tube to keep neutron response and probe weight to a minimum (the detector was designed for use in plutonium processing areas). Neutron response to a bare $\mathrm{Pu-Be}$ source is $\sim 1 \mathrm{c} / \mathrm{m} / \mathrm{mRem} / \mathrm{hr}$. By attaching the probe to the case, the instrument can be held in one hand for surface and smear-type monitoring, or it can be removed from the case for monltoring various locations and positions.

The only modification needed for the basic electronic package is a replacement meter faceplate which reads $0-500 \mathrm{c} / \mathrm{m}$. This provides three count rate ranges of 500,5000 , and $50,000 \mathrm{c} / \mathrm{m}$, and a register integrator for low count rates. The detector efficiency is 12\%, with a complete insensitivity to gamma radiation up to about $5 \mathrm{R} / \mathrm{hr}$.

\footnotetext{
** Du Pont's trademark for polyester film.

* Meter scale $1 \mathrm{~s}$ marked $1 \mathrm{n} \mathrm{mRem} / \mathrm{hr}$ and calibrated by applying a dose-equivalent of 10 to the $\mathrm{mrad} / \mathrm{hr}$ value measured by the neutron survey instrument.
} 


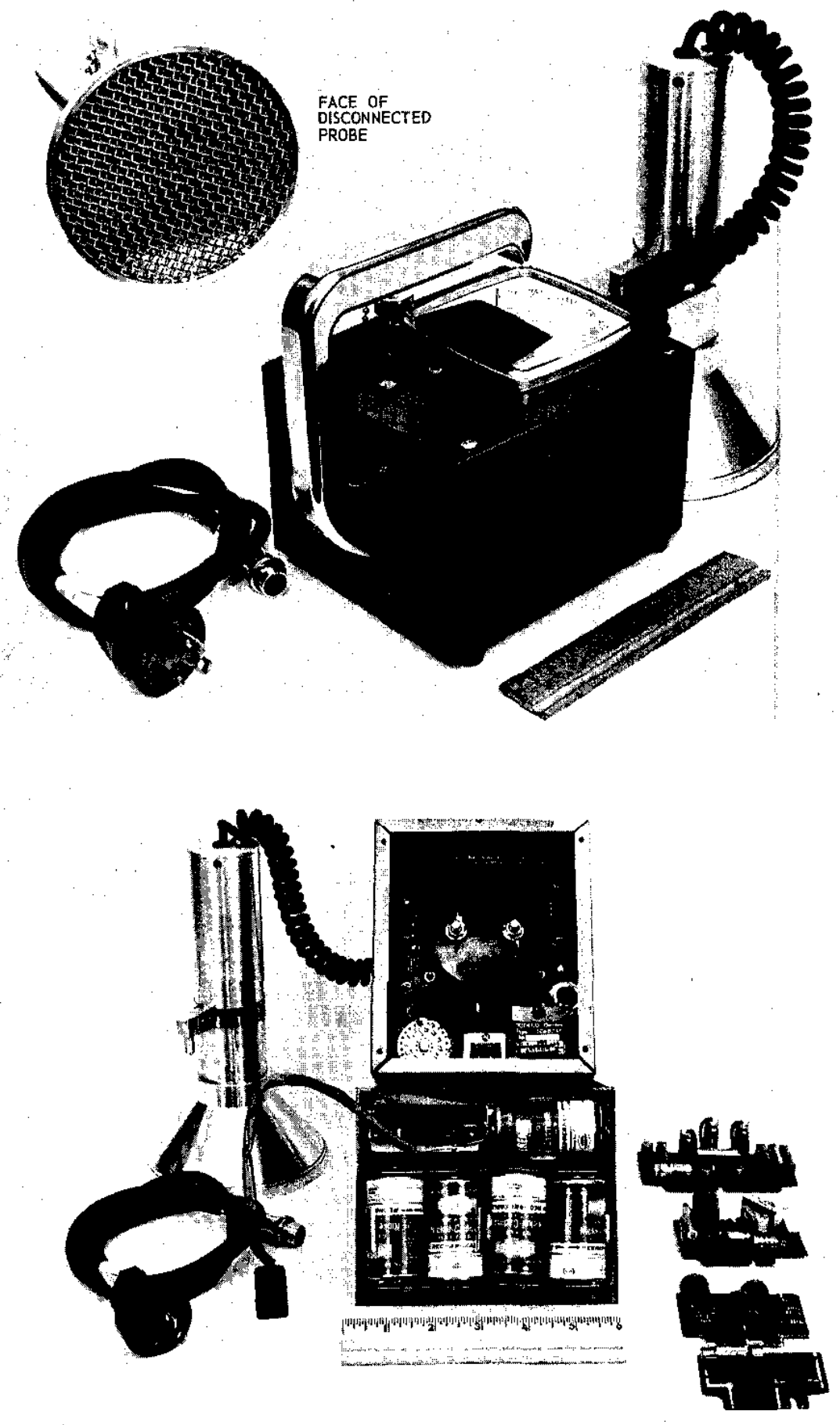

FIG. 4 ALPHA DETECTOR 


\section{BETA-GAMMA DETECTOR}

A Geiger tube was used with the basic electronics, in place of the scintiliation probe, to measure beta-gamma radiation (see Figure 5). Two minor modifications to the basic package made it compatible with the Geiger tube. To provide the 900 volts to place the tube on the Gelger plateau, a V1ctoreen type 5841 corona tube replaces $V_{1}$, the Victoreen type GV3A-1200 corona tube, and $R_{32}$ is adjusted to provide 900 volts. The meter faceplate $1 \mathrm{~s}$ modified to display readings of $0-500 \mathrm{c} / \mathrm{m}$. This provides three count rate ranges of 500, 5000, and $50,000 \mathrm{c} / \mathrm{m}$, and a register integrator for low count rates.

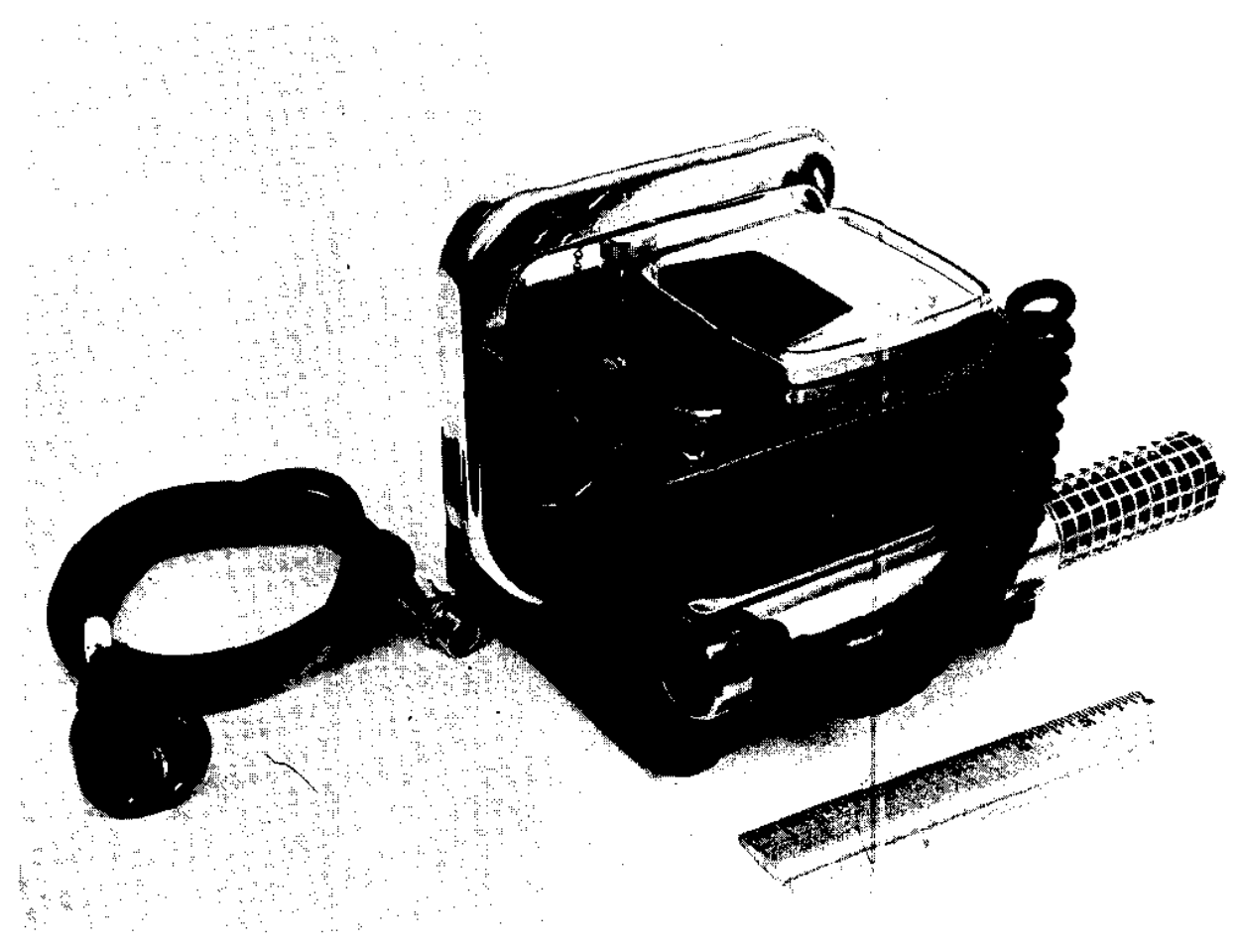

FIG. 5 BETA-GAMMA DETECTOR 


\section{ALPHA - BETA - GAMMA DETECTOR}

An alpha-beta-gamma survey probe (see Figure 6) was also used with the basic electronics package. The probe is a 1/16"thick x 1-1/2"-diameter NE-102 plastic scintillator (Nuclear Enterprises, Ltd.) sprayed on one side with $10 \mathrm{mg} / \mathrm{cm}^{2}$ of $\mathrm{ZnS}(\mathrm{Ag})$. The combination of $\mathrm{ZnS}(\mathrm{Ag})$ and plastic scintillator provide scintillating material for alpha, beta, and gamma radiation. The plastic scintillator acts as a light pipe between the $\mathrm{ZnS}(\mathrm{Ag})$ surface and the PM tube. The outward side of the plastic scintillator sprayed with the phosphor is covered with a single layer of 1/4-mil double aluminized "Mylar", to make the end of the probe lighttight. A 1-1/2" Dumont 6291 PM tube in intimate contact with the NE-102 scintiliator detects scintillations in both the $\mathrm{ZnS}(\mathrm{Ag})$ and the plastic scintillator. The probe can be removed from the case for monitoring, or the overall unit can be held in one hand for smear-type monitoring. Although this detector will

not identify the type of radiation, it has the advantage of responding to single or mixed radiation when monitoring for possible contamination.

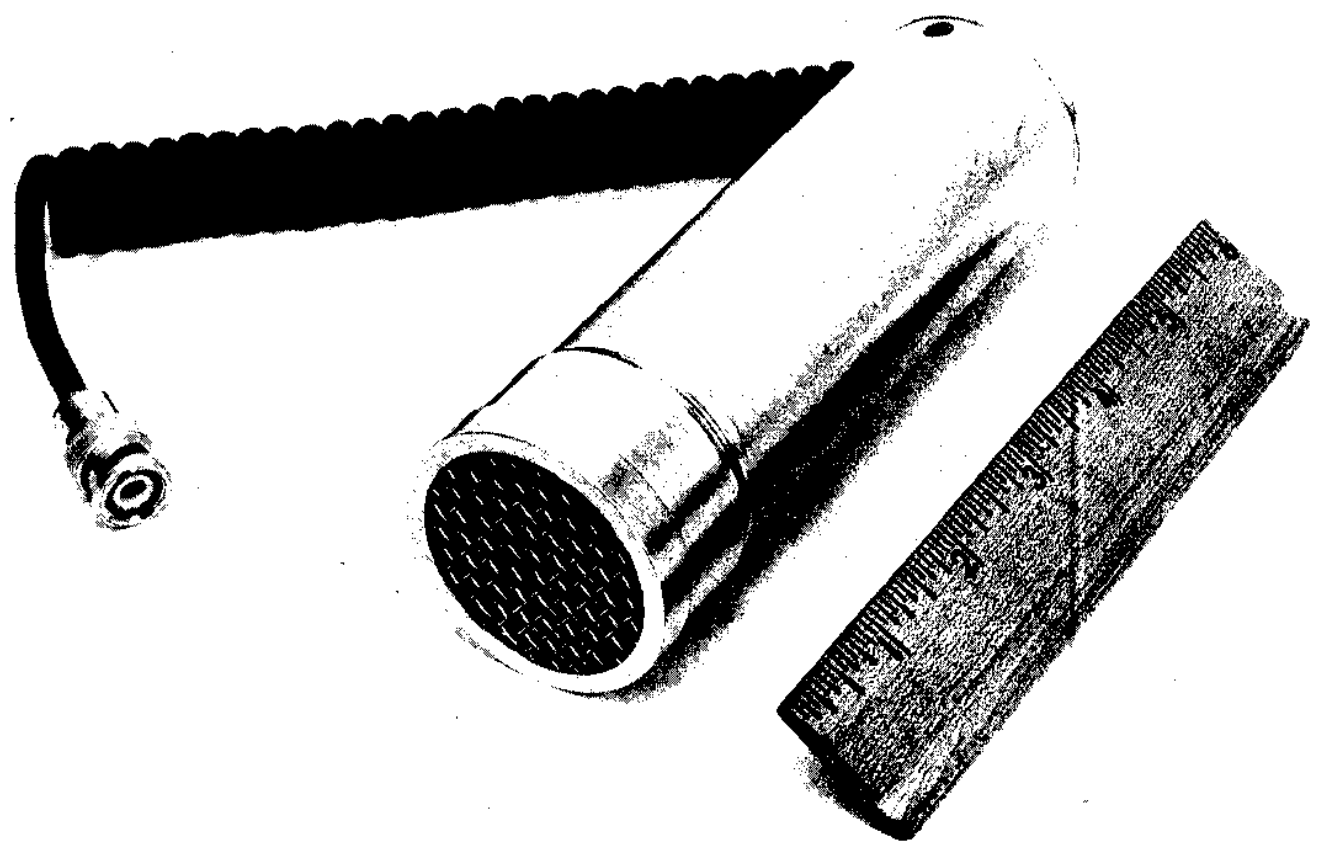

FIG. 6 ALPHA-BETA-GAMMA DETECTOR 
The only modification needed for the basic electronics package is a meter faceplate which reads $0-500 \mathrm{c} / \mathrm{m}$. Th1s provides three count rate ranges of 500,5000 , and $50,000 \mathrm{c} / \mathrm{m}$, and a register integrator for low count rates.

Conversion factors for this detector with the discrimination set to allow $1000 \mathrm{c} / \mathrm{m} / \mathrm{mR}$ of gamma radiation are as follows:

$\begin{array}{lc} & \frac{\mathrm{d} / \mathrm{m} / \mathrm{c} / \mathrm{m}}{} \\ \text { alpha }(5 \mathrm{Mev}) & 5 \\ \text { beta }{ }^{\circ 0} \mathrm{SrY} & 3 \\ \text { beta }{ }^{204 \mathrm{TI}} & 15\end{array}$

REFERENCE

(1) W. F. Hornyak. A Fast Neutron Detector. Rev. Sc1. Instr., $\underline{23}, 264$ (1952). 